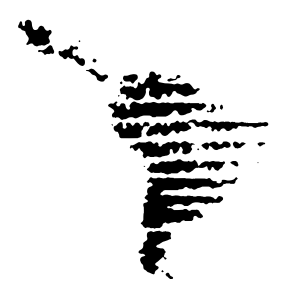

\title{
ALCANCE DEL PRINCIPIO DE NO DISCRIMINACIÓN DE LAS PERSONAS EN SITUACIÓN DE DISCAPACIDAD EN EL ÁMBITO DE LA EDUCACIÓN SUPERIOR EN COLOMBIA ${ }^{1}$
}

\author{
Angélica AndRade Villegas* \\ Tatiana Monsalve Mejía** \\ Kelly Viviana AristizÁbal GómEZ***
}

\section{Resumen}

El presente artículo tiene como finalidad identificar el alcance del principio de no discriminación de las personas en situación de discapacidad dentro del ámbito de la educación superior en Colombia, partiendo de un análisis riguroso, que inicia con una precisión del alcance y contenido del principio de no discriminación, continúa con la caracterización del panorama general del concepto de discapacidad y su evolución histórica, para finalmente desarrollar la incorporación de la normatividad internacional en el contexto colombiano y el correspondiente debate en torno a la educación superior inclusiva.

Palabras clave: personas con discapacidad, principio de no discriminación, inclusión educativa, educación superior, igualdad de oportunidades.

\section{Abstract}

This article aims to identify the scope of the principle of non-discrimination to people in disability condition in the field of higher education in Colombia, based on a thorough analysis which starts by précising the scope and content of the principle of non-discrimination, then it continues with the characterization of the general view on the concept of disabilities and its historic evolution to finally develop

1 Este artículo es resultado de la investigación denominada alcance del principio de no discriminación de las personas con discapacidad en las instituciones de Educación Superior en Colombia, adelantada en el programa de Derecho de la Universidad del Magdalena de la ciudad de Santa Marta, Colombia.

* Estudiante del programa de Derecho de la Universidad del Magdalena, Santa Marta, Colombia.

** Estudiante del programa de Derecho de la Universidad del Magdalena, Santa Marta, Colombia.

*** Abogada, especialista en asuntos de Derecho público y Derecho laboral, Magister en Derecho, docente y miembro del grupo de investigación gestión, gobierno y políticas públicas del programa de derecho de la Universidad del Magdalena de la ciudad de Santa Marta, Colombia. tutora de la investigación denominada Alcance del principio de no discriminación de las personas con discapacidad en las Instituciones de Educación Superior en Colombia. 
the incorporation of the international normativity in the Colombian context and the appropriate discussion on inclusive higher education.

Keywords: people in situation of disability, principle of non-discrimination, education inclusion, higher education, equal opportunities.

A través de este estudio se buscó dar solución a la siguiente pregunta problema: ¿Cuál es el alcance del principio de no discriminación en los casos de las personas en situación de discapacidad dentro del ámbito de la educación superior en Colombia? De esta manera un grupo de estudiantes universitarios comenzaron a debatir por qué en las aulas y en el campus universitario es escaza la presencia de estudiantes que presentan limitaciones funcionales. Así, las dudas e interrogantes cada vez se hacían más profundos, dándole inicio a una investigación rigurosa donde se constató la necesidad de crear una cultura protagónica de reflexión y trasformación sobre una problemática que se concentra en la falta de efectividad de recursos y mecanismos utilizados por las instituciones de educación superior para garantizar la "inclusión" de personas que presentan limitaciones físicas, sensoriales y psíquicas, teniendo en cuenta que dicho problema social es de gran relevancia a nivel internacional, pero a nivel nacional no corre con la misma suerte.

El concepto de discapacidad ha sido una constante evolución de modelos de tratamiento social que tienen sus antecedentes desde tiempos muy remotos. La apreciación de esta condición fue cambiando con el transcurso de las diferentes épocas pero siempre ligada a una particular característica que distingue a las personas que no se encuentran en situación de discapacidad de aquellas que presentan limitaciones funcionales, esto, evidentemente, los cohíbe de realizar sus actividades básicas cotidianas. A esta particularidad se le llamó "discriminación" la cual siempre está sellada por "la exclusión", de modo que impiden o anulan el reconocimiento, goce o ejercicio por parte de las personas en situación de discapacidad de sus derechos humanos y libertades fundamentales.

Siendo las personas con discapacidad objeto de discriminación y exclusión por parte de los miembros de la sociedad a lo largo de los años, a pesar de tener un marco jurídico políticamente legitimado que tiene como finalidad, otorgarle a estos seres humanos oportunidades e inclusión educativa, con este artículo de investigación lo que se pretende demostrar de manera específica es la ausencia o existencia de unas políticas institucionales que aseguren el ingreso y permanencia del estudiante con discapacidad y, por consiguiente, acrecienten la posibilidad de obtener el logro total de su autonomía y la mejora en sus condiciones de vida, igualmente, constatar que estas políticas no estén considerando a la discapacidad un producto de la conjugación de diferentes factores como lo social, lo cultural y lo 
epidemiológico que, finalmente, conlleva a la vulneración del principio de no discriminación.

Dicho lo anterior, es relevante mencionar que el enfoque del presente estudio es de carácter cualitativo, su alcance es descriptivo, se utilizaron como técnicas para alcanzar los resultados de investigación, la revisión de literatura especializada sobre el tema soportada en los correspondientes resúmenes analíticos de investigación y, por último, el análisis jurisprudencial demostrado en la realización de fichas de análisis jurisprudencial.

De esta manera, el contenido del artículo desarrollará el principio de no discriminación; acto seguido se estará hablando de manera muy concisa sobre el panorama del concepto de discapacidad, su historia y preponderancia del modelo social actual empleado por Colombia; consecuente con lo anterior, es importante hacer mención de qué manera la Convención y la legislación colombiana han tratado de convertir los espacios de exclusión de la personas en situación de discapacidad en escenarios de igualdad para todos y de esa manera cómo se ha pretendido llevar ese marco normativo a la realidad universitaria; por último, presentar propuestas que permitan dar soluciones para enfrentar la problemática de una educación exclusiva y discriminatoria de las personas con discapacidad en las instituciones universitarias.

\section{Resultados de investigación}

\section{Principio de no discriminación: un análisis a su alcance y contenido}

El principio de no discriminación surge de la necesidad universal de garantizar la igualdad de trato entre los individuos, a raíz "de la acumulación de diferentes sucesos injustificables que azotaron la humanidad como el holocausto y el asesinato de más de 6 millones de judíos" (Bayefsky, 1990, p. 2). Esto provocó que "los Organismos Internacionales, en las últimas décadas, aboquen de manera continua el desarrollo y promulgación del derecho a la igualdad" (Rannauro, 2011, p 206), elevándolo a la categoría de iuscogens, lo que implica que este sea el soporte de la mayoría de ordenamientos jurídicos y, por supuesto, de los Derechos Humanos. Sin embargo, establecer el alcance del principio de no discriminación no es una tarea fácil, puesto que en la actualidad existen diversas perspectivas del mismo. En algunos casos, como por ejemplo el caso colombiano, el principio de no discriminación es considerado como "el aspecto o dimensión negativa del derecho a la igualdad, que obliga a todas las autoridades del Estado (Corte Constitucional, sentencia T-199 de 2013, pág. 24)) y por esa razón cualquier acto vulnerador al derecho de la igualdad es considerado como discriminatorio. De manera opuesta, en el Estado español, el principio de no discriminación es un concepto autónomo, específico y concreto y, en tal 
virtud, es dable colegir que "no toda vulneración del derecho a la igualdad constituye un acto discriminatorio, pero toda vulneración del principio de no discriminación constituye una afectación al derecho a la igualdad". (Bilbao, 1997, p. 283, 325).

Siguiendo la línea argumentativa del Estado colombiano, el contenido del principio de no discriminación fundamentado en el artículo 13 de la Constitución Política consiste en dar una definición de discriminación y promover, a su vez, la realización de ajustes razonables para la consecución de acciones positivas llamadas -medidas de discriminación inversa-, la cual Campoy (2004, p. 12) manifiesta que dichas medidas en la Ley española 51/2003, arts. 1, 4, 5 "están orientadas a evitar o compensar las desventajas de una persona con discapacidad para participar plenamente en la vida política, económica, cultural y social" y estas, a su vez, no pueden apartarse de la justicia y la razón, vale decir, que "no pueden perseguir fines arbitrarios, caprichosos, despóticos o que, de alguna manera, repugnen a la esencial unidad y dignidad de la naturaleza humana" (Corte Constitucional, sentencia C-339 de 1996, pág. 11). Estas medidas deben someterse a un test estricto de razonabilidad que se compone de categorías llamadas "criterios sospechosos de discriminación" (Corte Constitucional, sentencia T-314, 2011, pág. 3) los cuales, si se llenan o se cumplen, constatan la incursión en una conducta injusta y arbitraria que restringe el derecho a la igualdad.

\section{Desarrollo jurisprudencial constitucional del principio de no discriminación}

1. "La jurisprudencia constitucional en materia de no discriminación y respuestas a la discapacidad está situada en un híbrido entre el modelo médico-rehabilitador y el modelo social-eliminador de barreras", (Corte Constitucional, sentencia $\mathrm{T}$ 1258, 2008, pág. 10).

2. La noción de discapacidad ha sido un proceso lento y difícil, en virtud del principio pro homine se ha optado por un enfoque amplio de la definición de discapacidad.

3. La Corte, ubicándose en el enfoque social, plantea el uso de un lenguaje inclusivo y respetuoso de la dignidad de las personas en situación de discapacidad lo cual resulta esencial para la comprensión de la discapacidad y la eliminación de pautas tradicionales de discriminación. En tal sentido, "la Sala adopta las convenciones lingüísticas para el enfoque del problema proporcionadas por la Organización Mundial de la Salud (OMS) que brindan un lenguaje unificado y positivo de las condiciones de salud de una persona" (Corte Constitucional, Sentencia T 1258, 2008, p 32.). 
4. La Sala reitera la condición como sujetos de especial protección constitucional a las personas con discapacidad, en atención a la creciente aceptación del modelo social de protección en el derecho interno, por lo tanto, se señala que las medidas internas deben fomentar la participación de las personas con discapacidad, deben (i) garantizar la participación de los interesados en el diseño y estructuración de los programas; (ii) tomar en cuenta los principios de diseño universal, accesibilidad para todos y todas, y ajustes razonables; (iii) promover la toma de conciencia y (iv) no construirse mediante esquemas discriminatorios. Lo cual incluye el ofrecimiento de recursos, infraestructura y estímulos adecuados. (Corte Constitucional, sentencia T-340, 2010, pág. 4).

\section{Relación del principio de no discriminación con la trascendencia de los imperativos clásicos del derecho a la igualdad en el ordenamiento jurídico colombiano}

El derecho a la igualdad constituye un "derecho subjetivo ya que es una facultad o atributo inherente a toda persona para no ser objeto de discriminación, vale decir, a un trato basado en diferencias arbitrarias" (Nogueira, 2006, pág. 89), así pues, este hecho permite el surgimiento del principio de no discriminación como uno de los derechos más básicos del ser humano.

Con el trascurso del tiempo, se ha evidenciado que el ordenamiento jurídico actual ha tenido cambios significativos, así pues, "el principio de igualdad de trato, responde a 2 corrientes" (Carmona, 1994, p, 5), la igualdad formal que consiste en el derecho que tienen todos los ciudadanos a ser tratados de igual manera, sin discriminaciones y la igualdad sustancial o material, que parte de las diferencias reales existentes entre los grupos tratados desigualmente y que legitima la introducción de desigualdades para restablecer la igualdad socialmente ignorada; por tanto, de ahí surge la idea de "igualdad con diferenciación". Estando así las cosas, si bien es cierto como lo afirma Nogueira (2012) que:

El principio de no discriminación enlaza con los valores inherentes a la dignidad de la persona humana y parte de la constatación de la existencia de grupos tradicionalmente marginados, con lo que su vulneración supone, pues no solo sitúa a sectores de la población en situaciones desventajosas carentes de razonabilidad, sino que también dichas vulneraciones son contrarias a la dignidad de la persona. (Pág. 6).

"Este mismo implica una prohibición más cualificada de la igualdad que debe ser corregida y eliminada, exigiendo, incluso un trato desigual o acción positiva para lograr que la igualdad de los 
colectivos marginados sea real y efectiva". (Nogueira, 2012, p. 7)

\section{Aplicación del principio de no discriminación e integración social en los casos de las personas con discapacidad.}

Los estados que ratifican tratados y convenios internacionales, lo hacen bajo el principio universal pacta sunt servanda, por lo tanto, su cumplimiento es de carácter obligatorio y vinculante. En esta medida, la Convención Internacional sobre los Derechos de las Personas con Discapacidad, y en sí, todo el sistema americano de protección a las personas que se encuentran en situación de discapacidad, establece una serie de obligaciones para los estados "con el objeto de que las personas con limitaciones no tengan que sumar a su circunstancia y a la marginación a la que usualmente se ven sometidas, una carga adicional a la que deben soportar los habitantes de la ciudad" (Corte Constitucional, sentencia T-551, 2011, p 35). Se establecen estas obligaciones con la finalidad de otorgar "igualdad de oportunidades, adaptación profesional, estabilidad laboral reforzada, condiciones adecuadas del ambiente construido y toma de medidas por parte de los estados, para eliminar todas las formas de discriminación de estas personas, así como para propiciar su plena inclusión en la sociedad" (Corte Constitucional, sentencia C-824, 2011, p 2). En últimas, desconocer esta situación contradice el postulado mínimo de igualdad y la idea elemental de un orden justo.

\section{Panorama general de discapacidad}

Evolución histórica del concepto de discapacidad y tratamiento social de manera universal

\section{Modelo de prescindencia}

En torno a este modelo, que se vio reflejado durante la época de la Antigüedad y la Edad Media, como lo puntualiza Palacios (2008):

Son dos las características del mismo. El primer distintivo hace referencia, que el origen de la discapacidad deviene de un hecho religioso: es un castigo de los dioses por un pecado cometido generalmente por los padres de la persona con discapacidad, o una advertencia de los dioses acerca de que la alianza se encuentra rota y que se avecina una catástrofe. La segunda particularidad parte de la premisa que en la sociedad las personas que presentan discapacidad no tienen nada que aportar a la misma.

Puesto que para la realización de sus actividades, la disminución en su capacidad no les permitía desarrollarlas, estos dependían de sus padres o de la propia comunidad. Así pues, al tomar como referencia a Palacios (como se citó en Velarde, 2011) que indica que a raíz de la condición de castigados e innecesarios, que rotulaba a los discapacitados, surgieron dos consecuencias que dieron origen a dos submodelos dentro del modelo de prescindencia: el eugenésico y el de marginación. 


\section{Submodelo eugenésico}

Desde la perspectiva de este submodelo, se dice que las personas con discapacidad al presentar una diversidad funcional, es decir, una enfermedad congénita no merecen ejercer su derecho a la vida y, en tal sentido, era valedero que la propia población aplicara sobre ellas métodos eugenésicos, o sea, se les diera muerte como ocurría en el caso de los niños, que se empleaba con ellos el infanticidio en la medida en que si bien se les detectaba su incapacidad para desarrollarse de forma normal y convertirse en un ciudadano completo, era propio del Estado dar su autorización para aquello, dado que sobre él recaía poderes de decidir referentes a la vida o muerte de sus futuros ciudadanos. Un ejemplo de la utilización del método eugenésico era "el caso de Esparta, donde los recién nacidos eran examinados por la Gerusía, el concejo de ancianos, quienes, si encontraban en ellos algún defecto, lo despeñaban desde el monte Taigeto." (Velarde, 2011, pág. 5).

\section{Submodelo de marginación}

Antes de darle inicio a la caracterización a este submodelo hay que señalar que la aparición del cristianismo en la Edad Media y con ello la penalización del infanticidio fue lo que propició un cambio en la situación de los discapacitados y, por ende, introdujo el submodelo de marginación. Ahora bien, este submodelo se caracterizó por excluir, en definitiva, a las personas en estado de discapacidad de la comunidad, en general, a causa de considerarlas como la consecuencia del pecado original, obra del diablo. Lo anterior fue lo que suscitó la aplicación de un tratamiento dado a las personas con discapacidad durante la Edad Media, que consistía en incluirlas dentro del grupo de los pobres y los marginados. En pocas palabras,

Aun cuando en este submodelo, gran parte de los niños y niñas con discapacidad mueren como consecuencia de omisiones básicas. Se dice que los que sobreviven o los mayores, están expuestos u/o están obligados partiendo de un medio de subsistencia impuesto, a la caridad de los ricos, a el ejercicio de la mendicidad y a ser objeto de burla y diversión. (Toboso, 2008, p. 3).

\section{Modelo rehabilitador}

En virtud de la Primera Guerra Mundial en el siglo XX y de la creación de las primeras legislaciones en torno a la seguridad social, surge el modelo rehabilitador con un nuevo concepto de discapacidad. En este sentido, desde la perspectiva de este modelo las causas que originan la discapacidad ya no son religiosas sino son médico-científicas, pues el término discapacidad en su extensión alude una enfermedad o en palabras de Toboso (2008, p. 4) "ausencia de salud". De acuerdo con lo anterior, el modelo rehabilitador permite que se sustituya la innecesaridad de las personas en situación de discapacidad utilizado en el modelo de 
prescindencia por la rehabilitación de las mismas ya que a partir de este paradigma "la discapacidad se concibió tomando como referencia el daño y/o perjuicio como una insuficiencia, una deficiencia que necesitaba ser normalizada o erradicada" (Jiménez, 2010, p. 4) a través de un proceso de normalización con la finalidad de obtener una supuesta identidad "normal" de aquel que presentaba la discapacidad y, a su vez, su integración social.

\section{Modelo social}

A través de este modelo, se establece que las causas que originan la discapacidad no son religiosas o científicas, como se mencionó en los modelos indicados anteriormente, sino que es meramente social, por cuanto a que parte de la premisa de que la discapacidad "es una construcción y un modo de opresión social, y el resultado de una sociedad que no considera ni tiene presente a las personas con discapacidad" (Palacios y Bariff, 2007, p 19). Ello quiere decir, que este modelo es aquel que apunta a que es la misma sociedad la que estigmatiza o señala a las personas con limitaciones como discapaces y los excluye de las diferentes actividades sociales.

\section{Preponderancia del modelo social en la actualidad}

\section{Definición actual de discapacidad}

A raíz del establecimiento del modelo social, la discapacidad "es el resultado de la interacción de la persona y su entorno" (Byrnes et al, 2007, p.4), por eso la discapacidad no es algo que radique en el "ser" de la persona como resultado de alguna deficiencia.

En la Constitución Política Colombiana de 1991 no existe una definición concisa de discapacidad y en diversas ocasiones en la Carta Magna se utilizan términos como: personas con limitaciones (art.68), personas en situación de debilidad manifiesta (art.13), disminuidos (art.47), minusválidos (art 54), entre otros. Por ello, la Corte Constitucional Colombiana en sentencia C-824 de 2011, concluyó que la elaboración de una noción de discapacidad ha sido un proceso muy lento y difícil y que, de hecho, hoy por hoy, se trata de un concepto en permanente construcción y revisión, por lo cual, es usual encontrar legislaciones internas que no se adecuan a los avances científicos en materia de discapacidad (pág. 3).

Sin embargo, la Corte Constitucional se ha referido a la discapacidad en los siguientes términos "La discapacidad es la deficiencia física, mental, o sensorial ya sea de manera permanente o temporal, que limita la capacidad de ejercer una o más actividades esenciales de la vida diaria, que puede ser causada o agravada por el entorno económico y social" (Corte Constitucional, sentencia C 293, 2010, pág. 40).

Esta construcción conceptual se tomó de la definición propuesta por 
la Convención Interamericana para la eliminación de todas las formas de discriminación contra Las personas con discapacidad. Ahora bien, la Convención Internacional sobre los Derechos de las personas con discapacidad (1999, artículo 1), incluye en la definición a aquellas personas que tengan deficiencias mentales, intelectuales o sensoriales a largo plazo que, al interactuar con diversas barreras, puedan impedir su participación plena y efectiva en la sociedad, en igualdad de condiciones con los demás.

Por otro lado, la Corte Constitucional ha dicho que hay una diferencia significativa entre discapacidad e invalidez, afirmó que la discapacidad es el género, mientras que la invalidez es la especie, por lo tanto, no siempre que exista discapacidad necesariamente nos encontramos frente a una persona inválida. (Corte Constitucional, sentencia T-1998, 2006, pág. 30). La jurisprudencia ha recalcado que la discapacidad es el objeto de especial protección y esta no puede estar limitada por la declaración de la invalidez, la cual "se limita a reconocer el grado o intensidad de la misma y sus efectos" (Correa, 2009, p.121).

\section{Adaptación de la legislación mundial al modelo social: relevancia del derecho a la educación}

La elaboración de normas uniformes basadas en un modelo social, sobre la igualdad de oportunidades para las personas con discapacidad ha tenido y tiene repercusiones a escala global, puesto que aparte de la evolución del derecho internacional, "los Estados partes en sus legislaciones internas se han ido adaptando poco a poco a una perspectiva de la discapacidad basada en los Derechos Humanos" (Degener y Quinn, 2000, pág. 20).

En los años 90, las leyes europeas propendían por un modelo rehabilitador para el tratamiento de las personas con discapacidad, por tal razón a las personas con algún tipo de discapacidad se les negaba el derecho de ser ciudadanos titulares de derecho, además, estas leyes desalentaban de manera contundente la inclusión de las personas con discapacidad en la vida pública, Timothy Cook (2002) en su artículo "A Little History Worth Knowing" cita ejemplos de las palabras y expresiones que existían en las leyes de los Estados, las cuales mostraban cierto grado de discriminación al referirse a las personas con discapacidad. En el siglo XX después de las guerras el movimiento de vida independiente venía exigiendo derechos en lugar de beneficencia y la respuesta se dio a través de leyes antidiscriminatorias, es así como "nacieron 3 periodos de políticas modernas que introdujeron el modelo social y fueron aislando el modelo rehabilitador" 1) Periodo: Se ubica tras la Primera Guerra Mundial en el que se introdujo la primera legislación de servicios sociales para los veteranos de guerra con discapacidad. 2) Periodo: Se ubica en la década de los 70, extendiendo la legislación de 
servicios sociales a todas las personas con discapacidad. 3) Periodo: Comenzó en los años 90 cuando algunos países europeos adoptaron una legislación antidiscriminatoria para las personas con discapacidad. (Degener y Quinn, 2000).

Al adoptar una legislación antidiscriminatoria, se vuelve absolutamente necesario hablar de igualdad de oportunidades donde la "inclusión" sea el fin primordial, y en esta medida el derecho a la educación se vuelve la piedra angular. La educación inclusiva hizo su primera aparición durante la Conferencia mundial sobre necesidades educativas especiales en Salamanca en 1994, esta fecha simboliza el punto de quiebre entre el paradigma anterior, asociado exclusivamente con la integración a la educación de las personas con discapacidad para eliminar todo tipo de -barreras- relativas al proceso de aprendizaje, y el inicio de una "Educación Para Todos" (Ministerio de Educación Nacional, 2013) a través de esta conferencia se tomaron las primeras medidas para garantizarles a la(s) persona(s) con limitación(es) lo siguiente:

Que los estados aseguren la igualdad de acceso a la educación primaria y secundaria, la formación profesional, la enseñanza de adultos y el aprendizaje permanente. Además, la educación debe emplear los materiales, las técnicas educacionales y las formas de comunicación adecuados. Los alumnos que las necesiten deben recibir las medidas de apoyo pertinentes, y los alumnos ciegos o sordos deben recibir su educación en las formas más apropiadas de comunicación, de maestros con fluidez en el lenguaje por señas y el Braille. La educación de las personas con discapacidad debe promover su participación en la sociedad, su sentido de dignidad y valor personal y el desarrollo de todo su potencial en lo que se refiere a la personalidad, los talentos y la creatividad (CDPD, 2007, pág. 1-2).

No obstante, desde una perspectiva teórica se opta por la inclusión; pero la práctica, normas y procedimientos de escolarización del alumnado con necesidades educativas especiales facilita la segregación de algunos de ellos en centros de educación especial, lo cual va en detrimento de la inclusión social y pedagógica, no solamente defendida por profesionales de la educación sino por muchas familias (Echeita, 2006).

Lo anterior evidencia la necesidad social de un cambio de paradigma en la mentalidad social y en la propia identidad de los centros educativos en relación con la educación inclusiva, "que persiste identificándose como una educación especial que aboga por la integración y no por la inclusión (López, 2004 y 2006, Stainback y Stainback, 2001).

Si se toma en cuenta que el punto álgido de este artículo de investigación se concentra en la relevancia de la educación para una sociedad inclusiva, es 
menester traer a colación la siguiente frase: "Dime y lo olvido, enséñame y lo recuerdo, involúcrame y lo aprendo" (Franklin, 1990, pág. 2). Esta anotación, para explicar que a la sociedad y a los centros educativos ya se les ha informado sobre la existencia de leyes que protegen a las personas con limitaciones, se les ha enseñado a través de programas, convenciones, seminarios, entre otros, pero no se les ha involucrado de manera rigurosa con la causa de la "inclusión social".

Leyes marco de protección a nivel internacional.

A nivel mundial e interamericano, existen dos convenciones que sientan precedente en lo referente a la protección de la personas con debilidades manifiestas. La Convención para la protección de los derechos de las personas con discapacidad -CPDPC- (2006) y La Convención interamericana para la eliminación de toda forma de discriminación contra las personas con discapacidad-CPEDCPD- (1999).

a. Propósito de la Convención internacional sobre los derechos de las personas con discapacidad

El artículo 1 de la Convención declara que el propósito de la misma es promover, proteger y asegurar el goce pleno y en condiciones de igualdad de todos los derechos humanos y libertades fundamentales por todas las personas con discapacidad, y promover el respeto por su dignidad inherente. b. Aplicación y vinculatoriedad de la Convención interamericana para la eliminación de todas las formas de discriminación contra las personas con discapacidad

Al firmar la Convención o el protocolo facultativo los estados u organizaciones regionales indican su intención de tomar las medidas pertinentes para quedar obligados por el tratado en una fecha posterior. Asimismo, la firma crea una obligación, en el periodo que transcurre entre la firma y la ratificación o consentimiento. El consentimiento de quedar obligado es el acto en virtud del cual los estados demuestran su disposición a aceptar las obligaciones jurídicas que se derivan de los instrumentos (Byrnes, et al.2007). Esta Convención fue aprobada por Colombia el 8 de junio de 1999. Entró en vigor: el 31 de Julio de 2002 a través de la ley 762 de 2002 (Organización de las naciones Unidas, 2012).

\section{De la exclusión a la igualdad: incorporación de la Convención interamericana para la eliminación de todas las formas de discriminación contra personas con discapacidad a la legislación colombiana}

Leyes marco de protección e inclusión social de las personas con discapacidad a nivel nacional

En materia de discapacidad es amplio el sistema de protección de los derechos de las personas que se encuentran en dicha situación, pues la legislación 
con la finalidad de trabajar por la inclusión social de las personas con limitaciones ha tenido una transición a lo largo de los años. Colombia ratifica la Convención internacional sobre los derechos de las personas con discapacidad, el 30 de marzo de 2007 y esta, entra en vigor a través de Ley 1346 del 2009. (ONU, 2012).

De este modo, es idóneo aludir, que si bien la Convención sobre los derechos de las personas con discapacidad (CDPCD) ha sido el logro jurídico y político internacional más importante de las personas en situación de discapacidad porque recoge las luchas y los cambios paradigmáticos que han experimentado con relación a las necesidades de las personas con discapacidad que se trataban desde la habilitación y la rehabilitación. (Correa, 2009), es propio que la ratificación por parte de
Colombia le permita, en palabras de Tromel (2008) al Estado desarrollar a profundidad los derechos humanos reconocidos a todos, con énfasis en las personas con discapacidad y establecer los deberes mínimos de éste, de la sociedad y de las familias.

En este sentido, Colombia es un país moderadamente incluyente, como uno de los diez países latinoamericanos, que "realiza algunas acciones a favor de la inclusión de la persona con discapacidad en varios ámbitos y da cumplimiento a varias de las normas que, en materia de inclusión, basadas en igualdad de oportunidades, se compromete a realizar" (Molina, 2010, p. 3) con base en la prerrogativa consagrada en la Constitución Nacional en su artículo 47 que señala que se dará protección para las personas con disminución física, sensorial, psíquica.

Tabla 1

Marco Legal de la Discapacidad en Colombia

\begin{tabular}{|c|c|c|c|c|c|}
\hline & $\begin{array}{c}\text { Inclusión } \\
\text { Social } \\
\end{array}$ & Salud & Cultura & $\begin{array}{l}\text { Subsidios y } \\
\text { Pensiones }\end{array}$ & Educación \\
\hline Ley(es) & 9 & 4 & 2 & 3 & \multirow{6}{*}{$\begin{array}{l}\text { Dec. } 1860 / 94 \\
\text { Ley } 115 / 94 \\
\text { Dec. } 2082 / 96 \\
\text { Dec. } 3011 / 97 \\
\text { Dec. } 672 / 98 \\
\text { Res. } 2065 / 03\end{array}$} \\
\hline Decreto(s) & 1 & 1 & - & 5 & \\
\hline Resolución(es) & - & 3 & - & 3 & \\
\hline \multirow[t]{2}{*}{ Plan(es) } & - & - & - & - & \\
\hline & Deporte & Comunicaciones & $\begin{array}{c}\text { Accesibilidad } \\
\text { Física }\end{array}$ & Trabajo & \\
\hline Ley(es) & 2 & 3 & 2 & 2 & \\
\hline Decreto(s) & 1 & - & 3 & - & Plan N./06 \\
\hline Resolución(es) & 1 & - & 1 & - & Dec. $366=09$ \\
\hline Plan(es) & - & - & - & - & \\
\hline
\end{tabular}

Nota: Normas de protección de las personas con limitaciones a nivel nacional de forma general con base en los art.13, 47, 54 y 68 de la Carta Magna. Se detalla la normatividad correspondiente a la educación en el margen izquierdo. Adaptado de: Gómez, N. (2013) Discapacidad y normas en Colombia. PDF, Recuperado de http:// es.scribd.com/doc/213922693/329-0-Discapaciada-y-Normas-en-Colombia-Natalia-Eugenia-Gomez-Rua 
Ahora bien, el marco legal colombiano consagra una cantidad considerable de leyes que buscan proteger a las personas con discapacidad en el plano nacional.

\section{Mecanismos de integración social: la educación como piedra angular}

La Constitución Política ha redignificado y principalmente ha garantizado la protección de los derechos de las personas con discapacidad, lo cual es coherente a todas luces con la legislación internacional, ya que aquella consagra las obligaciones básicas y concretas del Estado de eliminar la discriminación de esta porción no tan pequeña de la población colombiana, en tanto que "vulnera la dignidad humana y el principio de igualdad de todas las personas" (Eroles y Fiamberti, 2008, pág. 8). Ello derogando la vigencia de normas y prácticas excluyentes en función de la discapacidad, así como la implementación de acciones afirmativas para el logro de la igualdad material y la inclusión social.

No obstante, aunque exista una cantidad considerable de las políticas y reglamentaciones educativas para las personas con discapacidad en $\mathrm{Co}$ lombia, estas se han restringido a los lineamientos para la educación básica primaria y secundaria, y no se han hecho extensibles al nivel superior (Díaz, 2003). Siendo así, según Parra (2003), se ha olvidado que la esencia de acceder al nivel de educación superior, es tener la oportunidad de desarrollar habilidades sociales, aumentar los conocimientos y cualificarse para ingresar al mundo laboral, y contribuir así de una forma importante al desarrollo e inclusión en la sociedad. Si el objetivo es valorar la diversidad como riqueza y no como un problema, entonces la integración educativa no es suficiente, se necesita de una educación inclusiva en las IES, entendiendo que este término es mucho más amplio e implica que,

Todos los jóvenes y adultos de una determinada comunidad aprendan juntos, independientemente de su origen, sus condiciones personales, sociales o culturales, incluidos aquellos que presentan cualquier problema de aprendizaje o discapacidad. Se trata de una escuela que no pone requisitos de entrada ni mecanismos de selección o discriminación de ningún tipo, para hacer realmente efectivos los derechos a la educación, a la igualdad de oportunidades y a la participación. En la escuela inclusiva, todos los alumnos se benefician de una enseñanza adaptada a sus necesidades y no sólo los que presentan necesidades educativas especiales. (Parra, 2010, pág. 7).

\section{De las disposiciones a la práctica: debate en torno a la educación superior inclusiva}

\section{Dificultades en la operacionalización de las leyes en el ámbito de la educa- ción superior inclusiva}

\section{Mitos en cuanto a la educación inclusiva}


Tabla 2

Mitos en cuanto a la educación inclusiva y su ruptura

\begin{tabular}{c} 
MITO \\
\hline "La inclusión es impuesta en las escuelas por \\
ideologías extremistas y por padres que no son \\
realistas porque no aceptan que sus hijos sean \\
diferentes". \\
"Las personas a favor de la inclusión solo se \\
preocupan por los alumnos con discapacidad".
\end{tabular}

"Los defensores de la inclusión se apoyan solo en valores y filosofía, no existen investigaciones y datos. ¿La inclusión es una utopía?"

"El sistema educativo no está dividido. ¿Por qué se habla de sistemas paralelos?"

"Sin clases de educación especial, los alumnos con discapacidad no aprenderán las destrezas para una vida funcional".

"Para mantener la seguridad de los "personas especiales" es más conveniente que solo se relacionen entre sî".

"La inclusión es un favor que se hace a determinados alumnos a costa de otros niños".

Lleva años planificar y preparar antes de que se pueda empezar a practicar la inclusión.

"La inclusión valora los "objetivos sociales" sobre los "objetivos educativos".

\section{RUPTURA}

El gran esfuerzo de las asociaciones de padres ha llevado a reconocerles como "garantes de los avances" Orcasitas (2003), Además, 14 países del continente Americano han manifestado su apoyo político para la inclusión. Concluir que dichos padres y madres no son realistas es un error.

La inclusión no es únicamente beneficiosa para el alumnado con discapacidad, sino que también los beneficios son para el resto de los estudiantes (Fisher, (Roach y Frey, 2002), (McGregor y Vogelsberg, 1998).

Los estudios que han abordado el tema de la educación inclusiva a nivel mundial son numerosos concluye (Cardona y Chiner2006, pp. 287-306).

El sistema educativo sigue dividido y aún no se lleva a la práctica las condiciones idóneas para que todos los estudiantes puedan recibir una educación adecuada acorde a sus necesidades en la escuela ordinaria. Sin embargo, países como Alemania, Austria, Noruega, Dinamarca, Suecia y Finlandia marcan la diferencia.

Con la inclusión se pretende que el profesorado siendo creativo pueda encontrar maneras de incorporar habilidades de la vida funcional en los emplazamientos ordinarios, siendo beneficioso también para el resto de estudiantes. (Leire, et al. 2010).

La inclusión apuesta por la diversidad y se trata de educar respetando las diferencias. Además se parte de que cada persona es única y diferente al resto. (Leire, et al. 2010).

La inclusión no es un favor, sino un derecho de todas las personas a aprender en las mismas condiciones y lugares que el resto. (Leire, et al. 2010).

La inclusión es un proceso, no es un estado. Siempre surgen situaciones que necesitan una planificación, pero eso no impide que se vayan introduciendo pequeños cambios que ayuden a avanzar hacia prácticas más

Inclusivas. (Leire, et al. 2010).

El aprendizaje ocurre en un ambiente social en el que hay que aprender a hablar, a preguntar, entre otros aspectos. La educación inclusiva tiene como objetivos el desarrollo académico, social, emocional y moral. (Leire, et al. 2010).

Nota: En la Tabla 2 se exponen los principales mitos planteados por (Moriña, 2004) y los autores que han planteado una ruptura de estos. 
Figura 1

Proceso de la Educación Inclusiva en Colombia

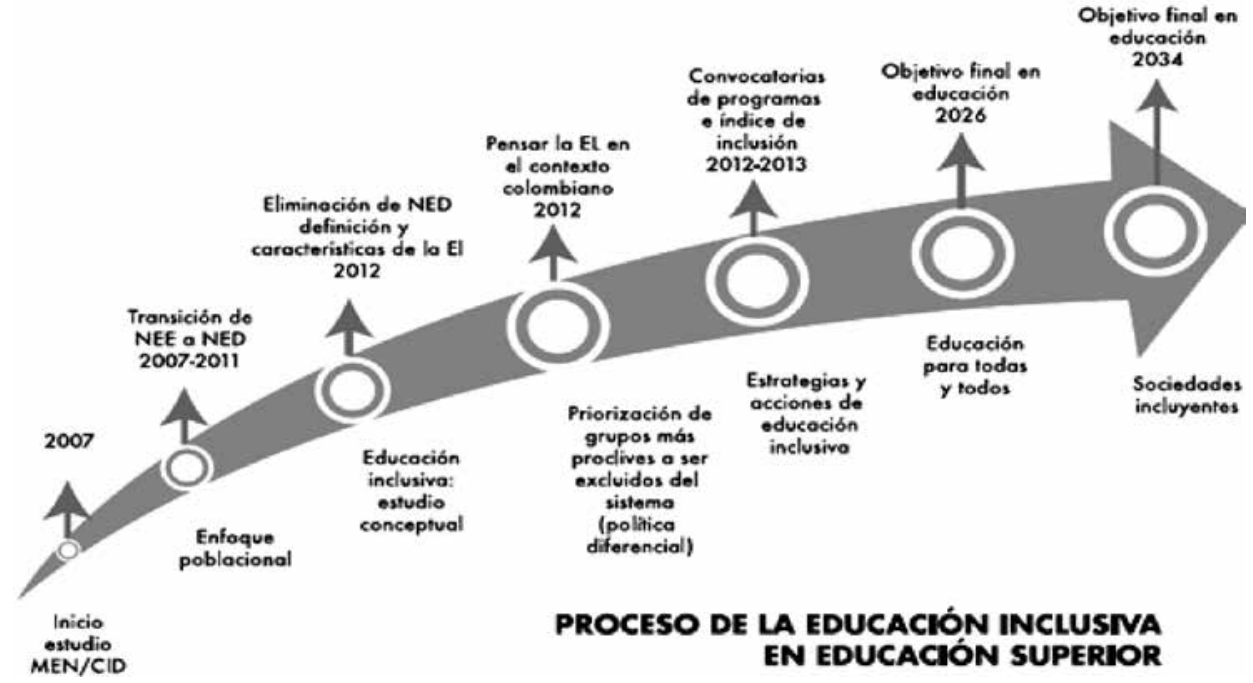

Fuente: Ministerio de Educación Nacional (2013) Dirección de Fomento para la Educación Superior: Lineamientos Políticos de Educación Superior Inclusiva. (Pág. 50) Bogotá, Colombia ISBN: 978-958-691-624-0

\section{Modalidades de la atención edu- cativa: ¿inclusiva o modestamente exclusiva?}

El proceso de educación inclusiva comenzó en el 2007, cuando el Ministerio de Educación Nacional (MEN) desarrolla un estudio junto con el Centro de Investigaciones para el Desarrollo de la Universidad Nacional de Colombia (CID), con el propósito de "analizar las condiciones de acceso, permanencia y graduación de la población diversa en este subsistema educativo" (MEN, 2013, pág. 38). Posteriormente, se realiza la transición de las necesidades educativas especiales (NEE) a necesidades educativas diversas (NED) con la finalidad de obtener un cambio de paradigma donde no solo se hablará de educación especial, sino de un modelo de educación que atendiera a otros grupos sociales de la sociedad colombiana. En el 2012 se elimina la expresión NEE, con base a un estudio conceptual de la educación inclusiva donde se establecieron sus características adaptadas al contexto colombiano, este estudio es muy importante, porque con él se estableció que,

La complejidad del contexto colombiano, la pluralidad de culturas y territorios, el conflicto armado y las múltiples expresiones de inequidad en las regiones obliga a "priorizar" una serie de grupos que son más proclives 
a ser excluidos del sistema educativo por circunstancias sociales, económicas, políticas, culturales, lingüísticas, físicas y geográficas, y que afectan los procesos de aprendizaje. (MEN, 2013, pág. 41).

Por lo tanto, al hablar de educación inclusiva en Colombia, no solo abarca a las personas con limitaciones, además de ellas, a aquellas con capacidades y/o talentos excepcionales, a los grupos étnicos (comunidades negras, afrocolombianas, raizales y palenqueras), a los pueblos indígenas, víctimas, población desmovilizada en proceso de reintegración, a la población habitante de frontera, entre otros grupos. Esto conlleva a que el proceso de educación inclusiva sea mucho más ambicioso y omnicomprensivo pero mucho más lento de lo normal, puesto que para que sea efectivo se tiene en cuenta "la priorización de grupos", sin embargo, el MEN plantea que los objetivos propuestos se alcanzarían en el 2026 y que se llegaría a una sociedad verdaderamente incluyente con educación para todos y todas hasta el 2034.

Para resolver la pregunta sobre si Colombia tiene actualmente una educación inclusiva, se tiene que pensar que el proceso se comenzó de manera reciente, por lo tanto, el camino que falta por recorrer es enorme y hay muchos retos por alcanzar. Es evidente que la sociedad y un gran número de IES, altamente selectivas, discriminatorias y excluyentes no tienen conocimientos profundos sobre esta problemática, en esa medida existen hasta el momento escazas garantías de que las personas con discapacidad puedan iniciar y culminar un proceso de educación superior de manera satisfactoria, por otro lado, se observan muchas limitaciones en cuanto a cobertura y calidad porque los docentes no están formados, ni hay una preparación adecuada de los establecimientos educativos.

\section{Principio de la autonomía universi- taria vs normativa de inclusión para la personas con discapacidad}

Las estrategias y acciones de educación inclusiva garantizan la autonomía universitaria velando por la calidad del servicio educativo, como lo estipula el artículo 3 de la Ley 30 de 1992. En la Constitución Política de Colombia dicha autonomía está consagrada en el artículo 28 de la Carta. Sin embargo, este principio es utilizado por algunas IES para justificar la falta de toma de medidas sobre el asunto de la discapacidad, como por ejemplo, la Universidad del Magdalena, la cual adujo,

Si bien es cierto el Consejo Superior de la Universidad no ha establecido una directriz que regule exoneración alguna para las personas en situación de discapacidad, ello no es obstáculo para que el actor se beneficie de los distintos estímulos que ofrece la institución como el reconocimiento a la excelencia académica, bachiller deportista, bachiller deportista galardonado nacional o internacionalmente, bachiller artista, matrícula de honor; 
primer, segundo, tercer, cuarto y quinto puesto, monitor académico, entre otras, cuando cumpla con los requisitos establecidos para el efecto.(Corte Constitucional, sentencia T-551, 2011, pág. 9).

En este sentido, el principio de autonomía universitaria está en contraposición con el artículo 24 de la Convención internacional sobre los derechos de las personas con discapacidad, el cual consagra que los Estados Partes asegurarán que las personas con discapacidad tengan acceso general a la educación superior, la formación profesional, la educación para adultos y el aprendizaje durante toda la vida sin discriminación y en igualdad sustancial de condiciones con las demás. A tal fin, los Estados Partes asegurarán que se realicen ajustes razonables para las personas con discapacidad.

Financiación de las instituciones de educación superior para la utilización de los recursos para la atención educativa apropiada

Entre las estrategias de financiación más significativas que se han tomado, se tiene que en el 2009 se lanzó la primera Convocatoria para el programa de innovación en educación superior para personas con discapacidad que pretende que las IES establezcan y diseñen mecanismos, que a través del uso de las TIC promuevan la inclusión educativa. Después de un riguroso proceso de evaluación de las 24 propuestas presentadas a la convocatoria fueron elegidas 5 iniciativas que apoya el MEN hasta con ochenta millones de pesos (\$80.000.000). Esto demuestra que se están dando los primeros pasos para que la educación en Colombia deje de ser moderadamente exclusiva y se convierta en una educación plenamente incluyente.

\section{Restructuración del entorno y capa- citación social}

En la sociedad actual, la idea que desenvuelve la reestructuración del entorno en el cual viven las personas con discapacidad, está dirigida inicialmente a cada una de sus familias. Sin embargo, aun cuando la familia es el primer entorno donde sus miembros a partir de sus vivencias desarrollan su nivel afectivo y social; se piensa que es difícil cambiar el entorno familiar, dado que "el nacimiento de un hijo con discapacidad supone un shock dentro de la familia. El hecho se percibe como algo inesperado que rompe las expectativas sobre el hijo deseado". (Sarto, 2001 p. 3). Por consiguiente, estando así las cosas es diminuta la posibilidad de aceptación de parte de las personas que integran la sociedad frente aquellas que están en situación de discapacidad, a pesar que "un entorno social accesible debe estar fundado en la concienciación de todos los miembros de la comunidad y la eliminación de perjuicios y actos discriminatorios". (Stupp, 2002, p. 22).

Por otro lado, trayendo a colación la integración que se le debe dar a las 
personas en estado de discapacidad en un modelo de universidades accesibles para todos orientadas de acuerdo a una política institucional emanada de estrategias en todos los ámbitos del quehacer universitario, se establece que son pocas las acciones que ejercen las universidades para promover una capacitación con el objeto de incluir a las personas con discapacidad en la enseñanza universitaria, ya que como lo indica Stupp (2002): "Es ineludible generar cambios internos necesarios para convertir a las instituciones, en modelos para la sociedad gracias a que el contenido de los reglamentos internos de las universidades está desactualizado". (Pág. 24).

En este mismo sentido, dice Alvarado (2002) que aunque los programas de servicios a estudiantes con discapacidad constituyen un apoyo importante en la Educación Superior, todavía no han logrado por sí mismos educar a profesores, estudiantes y personal administrativo en materia de discapacidad.

\section{Efectividad de las sanciones impues- tas por el ministerio de educación}

Los convenios y tratados internacionales ratificados por Colombia que protegen los derechos de la personas con discapacidad, exigen a los Estados "la obligación de evitar las medidas que impidan el disfrute del derecho a la educación" (Muñoz, 2010, pág31). Antes bien, siendo el Ministerio de Educación Nacional ente rector de la política educativa del país, considerando que ejerce una inspección y vigilancia de aspectos relacionados con las políticas y planeación del servicio educativo (MEN, 2014, pág. 2) se plasma a nivel jurisprudencial que la política pública sobre cómo garantizar el acceso y la permanencia en el sistema de educación superior de las personas en situación de discapacidad aún se encuentra en construcción por aquel, pero existe un consenso acerca de que dicha política debe desarrollar dos líneas: (i) el respeto por la diversidad y (ii) la importancia de una comunidad académica incluyente (Corte Constitucional, 2011).

Lo anterior, a consecuencia de que el Departamento Administrativo Nacional de Estadística (DANE) realizó un censo en el año 2005, a través del cual se logró establecer que el $6.3 \%$ de la población colombiana tiene alguna discapacidad de carácter permanente. De este porcentaje, el $33.3 \%$ no ha alcanzado ningún nivel educativo, el 29\% tiene estudios de básica primaria incompleta, el $2.34 \%$ ha accedido a algún nivel de educación superior (técnica, tecnológica o profesional), el $1 \%$ culminó sus estudios superiores y el $0.1 \%$ ha adelantado cursos de posgrado. (Parra, 2010).

\section{Afectación de la educación en el empleo para las personas con discapacidad}

Con la promulgación de Leyes de Igualdad de Oportunidades para las Personas con Discapacidad se ha intentado buscar la igualdad de 
oportunidades para esta población con alguna limitación intelectual, física o sensorial, dentro de los espacios laborales, educativos y sociales. Sin embargo, la escasa creación y aplicación de políticas nacionales, en los sistemas de educación superior que permiten desarrollar una educación inclusiva para las personas en situación de discapacidad ha impedido u ocasionado la poca participación de estos en el campo laboral puesto que Vega, López, Garín (2013) aseguran que los mismos sistemas educativos han contribuido con esta situación, no solo al formar las personas que hoy dinamizan una economía competitiva y excluyente, sino también al no dotar a las personas con limitaciones de aquellos recursos que les permitan integrarse en la sociedad.

\section{Conclusiones y propuestas}

Se puede afirmar que los problemas y desafíos planteados no derivan de la ausencia de una legislación apropiada, sino que radican en aplicación efectiva y concreta de esta, sin embargo, se tiene "que los discursos políticos han de ir calando en las distintas mentalidades y pasar de estas a la praxis educativa" (Paya, 2010, p. 16).

Países como Ecuador, Uruguay, Brasil, Costa Rica y Bolivia tienen importantes avances en lo que respecta a este tema (Crosso 2010, p. 79-95):

1. En el campo del financiamiento, un buen ejemplo es el Fondo Nacional de Desarrollo de la
Educación Básica (FUNDEB), en Brasil, que ordena el financiamiento de la educación en el país y que contempla que un 20\% o más de recursos públicos sean destinados a los alumnos/ as con discapacidad.

2. La existencia de consejos y otras instancias de debate y decisión es otra buena práctica a subrayar. En Costa Rica, el Ministerio de Educación Pública creó en el 2002 el Centro Nacional de Recursos para la Inclusión Educativa (Cenarec) como herramienta para brindar apoyo, asesoramiento, recursos, información, investigación y capacitación dirigida principalmente a docentes, padres y madres de familia, para facilitar el proceso de inclusión de los estudiantes con necesidades educativas especiales en el sistema de la educación regular.

3. En Ecuador, el Consejo Nacional de Discapacidades ha organizado una red de las Defensorías del Pueblo de cada provincia y con los consultorios jurídicos de las universidades previamente capacitadas, para que atiendan $\mathrm{u}$ orienten a las personas con discapacidad de manera que puedan utilizar ciertos mecanismos legales para defenderse y sancionar la violación de sus derechos.

4. En Uruguay realizan un concurso a nivel interno de las buenas prácticas en educación inclusiva, en donde las diferentes 
instituciones de educación en todos sus niveles, compiten por la mejor practica de educación inclusiva de manera anual, las experiencias escogidas, son publicadas posteriormente en un libro, los requisitos de las experiencias para concursar comprenden: el contexto institucional, la descripción de la experiencia que, a su vez, se compone de antecedentes relevantes, apoyo recibido, equipo de trabajo, entre otros; la descripción detallada de la experiencia y su correspondiente evaluación. Es una estrategia muy enriquecedora. (OEI, 2011).

Ahora bien, hacen falta:

1) Campañas de sensibilización a nivel del sistema educativo, con un mensaje dirigido a sostenedores, directivos, docentes, alumnos y apoderados, incentivando a que incluyan en sus comunidades escolares a alumnos con discapacidad.

2) En los programas de formación de profesores incluir la temática de la atención de alumnos con necesidades educativas especiales asociadas a una discapacidad, de forma que los docentes construyan los conocimientos, estrategias y actitudes necesarias para el desarrollo de escuelas inclusivas.

3) La malla curricular de la carrera de formación docentes debería contar con un tronco común (parvulario, básica, media y diferencial) lo que facilitaría un trabajo coordinado y en equipo durante el futuro ejercicio profesional.

4) Revisar el mecanismo de asignación de recursos a las experiencias de integración, en la perspectiva de agilizar el procedimiento y posibilitar un trabajo colaborativo más global por parte de los especialistas en el contexto de la escuela y el aula.

5) Construir redes entre IES y equipos que trabajen en integración educativa para el intercambio de experiencias y aprendizajes.

Por último, es muy importante resaltar el papel de los estudiantes universitarios en todo el proceso de educación inclusiva, ya que está en sus manos que un proceso de inclusión académica culmine con éxito: en primera medida, aceptando las diferencias sociales, eliminando los perjuicios y comprendiendo las capacidades que resaltan por encima de cualquier limitación humana, además de convivir de manera adecuada tanto el campus universitario como en el ámbito laboral y preocupándose cada día por aprender y compartir experiencias, para así implantar en las nuevas generaciones la semilla de una sociedad plenamente incluyente. Por otro lado, la comunidad universitaria debe avanzar en lo que compete a semilleros de investigación desde las diferentes disciplinas 
y campañas de sensibilización y aprendizaje para toda el alma máter y las comunidades aledañas a ella.

\section{Referencias}

Alvarado, M. (2002). Las luchas del movimiento de personas con discapacidad en la deconstrucción de paradigmas discriminantes. En Jiménez, R. (Ed.), Las personas con discapacidad en la educación superior (una propuesta para la diversidad e igualdad, San José, Costa Rica: Gossestra.

Bayefsky, A. (1990). El principio de la igualdad o no discriminación en el derecho internacional. En Human Rights Law Journal, 11 (1-2), 1-34. Recuperado de http:// www.corteidh.or.cr/tablas/r31086spa.pdf

Bilbao, J. M. (1997). La eficacia de los derechos fundamentales frente a particulares. Análisis de la Jurisprudencia del Tribunal Constitucional. Madrid: CECP.

Byrnes, A., Conte, A., Gonnot, J. P., Larsson, L., Schindlmayr, T., Shepherd, N., Walker, S. y Zarraluqui, A. (2007). De la Exclusión a la Igualdad-hacia el pleno ejercicio de los derechos de las personas con discapacidad. Ginebra, Suiza: Naciones Unidas.

Campoy, I. (2004). El reflejo de los valores de libertad, igualdad y solidaridad en la ley 51/2003, de 2 de diciembre, de igualdad, de oportunidades, no discriminación y accesibilidad universal de las personas con discapacidad. Revista Universitas, 73-98. Recuperado de http://e-archivo.uc3m. es/bitstream/handle/10016/8657/reflejo_campoy_RU_2004.pdf?sequence=1

Cardona M. y Chiner E. (2006). Uso y efectividad de las adaptaciones instructivas en aulas inclusivas: un estudio de las percepciones y necesidades formativas del profesorado. Bordón. Revista de pedagogía, 58(3), 287 -306.

Carmona, E. (1994). El principio de igualdad material en la constitución europea. Revista Estudios Políticos, (84), 265-286.

Cook, T. (1993). A little history worth knowing dialogue on disabilities. Mennonite Central Committee, Summer, 14 (3).

Corte Constitucional Colombiana, Sala Plena. Sentencia del 1 de agosto de 1996. M.P: Dr. Julio Cesar Ortiz Gutiérrez. (Sentencia C-339/96), pág. 11, párr. 4. Copia tomada directamente de la Corporación. Recuperado de http:// www.corteconstitucional.gov.co/relatoria/1996/C-339-96.htm\#_ftn1

Corte Constitucional Colombiana, Sala Plena. Sentencia del 10 de junio de 2003. MP: Dra. Clara Inés Vargas Hernández. (Sentencia C-478/03) p.44. Copia tomada directamente de la Corporación. Recuperado de http:// www.corteconstitucional.gov.co/relatoria/2003/C-478-03.htm

Corte Constitucional Colombiana, Sala Sexta. Sentencia de 16 de marzo de 2006. M.P. Marco Gerardo Monroy Cabra (Sentencia T-198-06). Pág. 30. Copia tomada directamente de la Corporación. Recuperado de http://www.corteconstitucional. gov.co/relatoria/2006/t-198-06.htm

Corte Constitucional Colombiana, Sala Quinta de Revisión. Sentencia del 15 de diciembre del 2008. M.P: Mauricio González Cuervo. (Sentencia T-1258 de 2008), p. 29. Copia tomada directamente de la Corporación. Recuperado de http:// www.corteconstitucional.gov.co/relatoria/2008/t-1258-08.htm 
Corte Constitucional Colombiana, Sala Plena. Sentencia del 21 de abril de 2010. MP: Dr. Nilson Pinilla Pinilla. (Sentencia C-293/10) p. 40 Copia tomada directamente de la Corporación. Recuperado de http://www.corteconstitucional.gov. co/relatoria/2010/C-293-10.htm

Corte Constitucional Colombiana, Sala Tercera de Revisión. Sentencia del 11 de mayo de 2010. M.P: Dr. Juan Carlos Henao Pérez. (Sentencia T-340/10), pág. 16. Copia tomada directamente de la Corporación. Recuperado de http:// www.corteconstitucional.gov.co/relatoria/2010/T-340-10.htm\#_ftnref18.

Corte Constitucional Colombiana, Sala Plena. Sentencia del 2 de noviembre del 2011. M.P: Dr. Luis Ernesto Vargas Silva. (Sentencia C-824/11), p. 2. Y 3 Copia tomada directamente de la Corporación. Recuperado de http://www.corteconstitucional. gov.co/relatoria/2011/c-824-11.htma

Corte Constitucional Colombiana, Sala Quinta de Revisión. Sentencia del 4 julio del 2011. M.P: Dr. Jorge Ivan Palacio Palacio. (Sentencia T-314/11), págs. 3, 37. Copia tomada directamente de la Corporación. Recuperado de http:// www.corteconstitucional.gov.co/relatoria/2011/t-314-11.htm.

Corte Constitucional Colombiana, Sala Séptima de Revisión de Tutelas. Sentencia del 7 de julio de 2011. M.P: Dr. Jorge Ignacio Pretelt Chaljub. (SentenciaT-551/11), pág. 28. Copia tomada directamente de la Corporación. Recuperado de http:// www.corteconstitucional.gov.co/relatoria/2011/t-551-11.htm\#_ftn19.

Corte Constitucional Colombiana, Sala Octava de Revisión. Sentencia del 10 de abril de 2013. M.P. Alexei Julio Estrada (Sentencia T-199/13), p. 24. Copia tomada directamente de la Corporación. Recuperado de http://www.corteconstitucional. gov.co/relatoria/2013/T-199-13.htm

Crosso, C. (2010). El derecho a la educación de personas con discapacidad: impulsando el concepto de educación inclusiva. Revista Iberoamericana de educación, (2), N. 6 63, 79-95.

Correa, L. (2009). Panorama de la protección jurisprudencial a los derechos humanos de las personas con discapacidad en Colombia. Revista Universitas, (118), pp.

Degenner, T. y Quinn, G. (2000). A Survey of International, comparative and Regional Disability law Reformenen from Principles to practice, an international Disability law and policy Simposium, organizado por DREDF. Recuperado de http://dredf.org/ simposium/degener1.html.

Díaz, O. C. (2003). Concepción de la atención educativa de personas con discapacidad. Documento de trabajo. Bogotá: Ministerio de Educación Nacional. Recuperado de http://186.113.12.12/discoext/collections/0032/0014/02690014.pdf

Echeita, G. (2006) Educación para la inclusión. Educación sin exclusiones. Madrid: Narcea. (pp.29).

Eroles, C. y Fiamberti, H. (2008). Los derechos de las personas con discapacidad: análisis de las convenciones internacionales y de la legislación vigente que la garantizan. (p.8) Recuperado de http://www.cud. unlp.edu.ar/uploads/docs/libro_eroles_fiamberti.pdf.

Fisher, D., Roach, V. y Frey, N. (2002). Examining the general programmatic benefits 
of inclusive schools. International Journal of Inclusive Education, 6(1), 63-78.

Jiménez, D. (2010). Concepto social de la discapacidad. Publicado en Corporación Síndrome de Down. (pp. 4).

Leire, A., Fernández, J. y Goicoechea, P. (2010). Congreso Iberoamericano de Educación, Educación Inclusiva iLa educación inclusiva como utopía que nos ayuda a caminar? Recuperado de http://www.chubut.edu.ar/descargas/secundaria/congreso/ EDUCINCLUSIVA/R1879_Darreche.pdf

Ley española 51/03. Tribunal Español. Jefatura del Estado. Art 1.Sección: I. Disposiciones generales. Ley del 02 de diciembre del 2003, de igualdad de oportunidades, no discriminación y accesibilidad universal de las personas con discapacidad. Pág 43189. Juan Carlos I Rey De España. Ref: BOE-A-2003-22066.

López M, M. (2006). La ética y la cultura de la diversidad en la escuela inclusiva publicado en Revista Redalyc. Recuperado de http://www.redalyc.org/articulo. oa? id=99815739002

. (2004). Construyendo una escuela sin exclusiones. España, Archidona (Málaga): Aljibe.

McGregor, G. and R. Timm Vogelsberg. (1998). Inclusive Schooling Practices: Pedagogical and Research Foundations. Baltimore, MD: Paul H. Brookes Publishing Co., Inc.

Ministerio de Educación Nacional MEN (2013). Lineamientos políticos de una educación Inclusiva (C) Ministerio de Educación Nacional ISBN: 978-958-691-624-0 Dirección de Fomento para la Educación Superior,
Pág. 19, Bogotá, Colombia.www.unesco. org/education/pdf/SALAMA_S.PDF.

Ministerio de Educación Nacional MEN. (2014). Funciones del Ministerio de Educación Nacional. Artículo 7.

Molina, R. (2010). Educación superior para estudiantes con discapacidad. Revista de Investigación (indexada). (p.3).

Moriña, A, (2004). Teoría y práctica de la educación inclusiva. Archidona:Aljibe.

Muñoz, V; Oficina Regional de Educación de la Unesco. (2010-2012). El derecho a la educación: una mirada comparativa. Santiago, Chile. (p. 31).

Nogueira, H. (2006). El derecho a la igualdad ante la Ley, La no discriminación y acciones positivas. REV - AD - N. ${ }^{\circ} 10$ (p.8).

(2012). El principio de igualdad y no discriminación en las relaciones laborales: Perspectiva Constitucional Reciente. Lan Harremanak. Revista de Relaciones Laborales. ISSN: 1575-7048. (p.6, 7).

Orcasitas, J, (2003). Congreso La respuesta a las necesidades educativas especiales en una escuela vasca inclusiva. Gustientzakoeskola. 20 años de integración escolar en el País Vasco: Haciendo historia..., construyendo un sistema educativo de calidad para todos. En Actas del Congreso (p. 26).

Organización de Estados Americanos (OEA) Sede Uruguay. (2011). Concurso de Experiencias: Buenas Prácticas en Educación Inclusiva en Uruguay. ISBN: 978-9974-36-209-3.

Organización de las Naciones Unidas ONU, (2006). Convención sobre los derechos de las 
personas con discapacidad, artículo N. ${ }^{\circ} 1$ de la Organización de las Naciones Unidas ONU, (2006), Instrumento Internacional.

Organización de las Naciones Unidas (ONU) (2012). Examen Periódico Universal EPU- 2012. Anexo III Tratados ratificados por Colombia a 2012. (pp. 53-57). Recuperado de http://www.derechoshumanos.gov. co/epu/Documents/130219-3-anexo3.pdf.

Palacios, A. y Bariff, F. (2007). La discapacidad como una cuestión de derechos humanos: Una aproximación a la Convención Internacional sobre los Derechos de las Personas con Discapacidad. Rev. CERMI. No. 04. (p.19).

Palacios, A. (2008). El modelo social de discapacidad: orígenes, caracterización y plasmación en la Convención Internacional sobre los Derechos de las Personas con Discapacidad, Rev. Colección CERMI. No. 36 (p.37).

Parra, C. (2003). Borradores de investigación. Población con discapacidad en Colombia. Aspectos sociales, económicos y políticos. Bogotá: Facultad de Jurisprudencia Universidad del Rosario. (p.76).

. (2010). Educación Inclusiva: un modelo de educación para todos. Revista

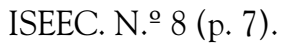

. (2010). Educación Inclusiva en Colombia. Un derecho para todos. Bogotá, Colombia. Universidad Sergio Arboleda. (p.33).

Paya, A. (2010) Políticas de educación inclusiva en América Latina: Propuestas realidades y retos de futuro, Revista Educación Inclusiva. Vol. 3 N. ${ }^{2}$ (p.16).

Rannauro, E. ( 2011). El derecho a la igualdad y el principio de no discriminación: la obligación del gobierno de México para realizar la armonización legislativa de la perspectiva de género. Revista. JUS. Vol. 5. (p. 206).

Sarto, M. P. (2001, febrero). Familia y Discapacidad. Ponencia presentada en el III Congreso "La Atención a la Diversidad en el Sistema Educativo". Salamanca. (p.3).

Stainback, S. y Stainback W. (2001): "Componentscrítics en el desenvolupament de l'educació inclusiva". DinsSuports. Revista Catalana d'Educació Especial i Atenció a la Diversitat. Vol. 5, núm. 1, (p. 26-31.).

Stupp,R. (2002).Universidades accesibles para todos. En Jiménez, R. (Ed.), Las personas con discapacidad en la educación superior (una propuesta para la diversidad e igualdad), San José, Costa Rica: Gossestra. (p. 22-24).

Toboso, M. (2008) La discapacidad dentro del enfoque de capacidades y funcionamientos de AmartyaSen. Revista Iberoamericana de Filosofía, Política y Humanidades. N.o 20. (p.3-4).

Universidad del Magdalena (2011) Sentencia T-551/11, con fecha de 07 de julio del 2011 M P.: Jorge Ignacio PreteltChaljub, Copia tomada directamente de la Corporación. Recuperado de http:// www.corteconstitucional.gov.co/relatoria/2011/t-551-11.htm.

Vega, A., López, M., Garín, S. (2013). La educación inclusiva: entre la crisis y la indignación. Revista Sociológica de Pensamiento Crítico Vol. 7, N. 1 . (p. 3).

Velarde, V. (2011). Los modelos de la discapacidad: un recorrido histórico. Revista empresa y humanismo, Vol XV / N. ${ }^{\circ} 1$ (p.5).

Recibido: 23/7/2014 • Aceptado: 2/3/2015 